ARTICLE

\title{
The Falklands/Malvinas war taken to the Wikipedia realm: a multimodal discourse analysis of cross- lingual violations of the Neutral Point of View
}

\author{
José Gustavo Góngora-Goloubintseff (D) ${ }^{1 凶}$
}

\begin{abstract}
Wikipedia is a multilingual collaborative, user-generated encyclopaedia. As the largest source of free knowledge on the Internet, Wikipedia is at the crossroads of diverse cultural and national groups largely characterised by distinctive ideologies. Such ideologies often converge and have for the most part contributed to the encyclopaedia's unprecedented success. Nonetheless, as several studies on Wikipedia have highlighted, the ideological stance of the authors is known to pose challenges to neutrality, often leading to "edit wars" that ultimately cast doubts on Wikipedia's credibility when presenting seemingly controversial subjects. Despite the copious amount of literature on neutrality in Wikipedia, little research has yet applied multimodal discourse analysis to tackle cross-lingual violations of the Neutral Point of View (NPOV). Consequently, this study draws on selected visual and textual data from the English and Spanish Wikipedia entries for the Falklands/Malvinas War to prove that the inclusion of certain images and lexemes in particular contexts can be good indicators of NPOV violations. The data set used in the research consisted of the introductory sections, table of contents and images from the two Wikipedia entries and a set of selected comments posted on their talk pages. The findings suggest that specific lexical and visual choices are ideologically motivated and go against the principles advocated by NPOV. This is further attested by the fact that some lexical choices are contested by Wikipedia editors on the talk pages, thus showing that neutrality in the user-driven encyclopaedia is a relative and local position.
\end{abstract}

\footnotetext{
${ }^{1}$ University of Manchester, Manchester, UK. ${ }^{凶}$ email: jose.gongoragoloubintseff@postgrad.manchester.ac.uk
} 


\section{Introduction}

aunched in 2001, Wikipedia is a multilingual, collaborative, peer-reviewed online encyclopaedia run by thousands of volunteers from almost every corner of the planet. The userdriven project is available in $>300$ languages and language varieties. At the time of writing, Wikipedia remains one of the ten most popular websites in the world, having held that position for over a decade (Alexa, 2020). The encyclopaedia's undisputed popularity as a source of primary information and the fact that anyone can modify or create new content at any time have turned it into a valuable resource (Michelucci and Dickinson, 2016). Perhaps unsurprisingly, Wikipedia's power and reach have led some fearful non-democratic governments around the world to restrict access to the site, either temporarily or permanently (Hobbs and Roberts, 2018; Zhang et al., 2017).

Powerful as it is, Wikipedia has often been criticised on the grounds that it is unreliable and biased, particularly in hotly contested areas such as religion and politics (Callahan and Herring, 2011; Hyman, 2011; Warncke-Wang, 2012). This seeming lack of reliability has prompted scholars from various fields to undertake research on content accuracy in Wikipedia. Some illustrative examples are Martin's (2017) analysis of persistent bias in one English Wikipedia entry, Azer's (2015) investigation of accuracy, quality and readability of Wikipedia entries on the respiratory system, and Warncke-Wang's (2012) comparative study of censorship and editorial bias among different language versions of Wikipedia.

Against this background, the aim of this paper is to tackle cross-lingual neutrality breaches in Wikipedia by conducting a multimodal discourse analysis of selected visual and lexical material, laying stress on their salient features and the repetition of certain lexemes. This, in turn, is accompanied by a critical analysis of postings on the associated "talk pages", public forums that provide a space for users to discuss editing issues (Page, 2014, p. 63). In doing so, I argue that the preference for specific visual material and the inclusion-or exclusion-of certain lexemes in two Wikipedia entries about the same subject can be used as another way to account for violations of Wikipedia's Neutral Point of View (hereinafter NPOV). According to NPOV, all entries should be written using neutral language and, when possible, all significant viewpoints ought to be fairly represented, thus guaranteeing an impartial and proportional coverage of the subject (Wikipedia, 2019a). Notwithstanding, previous research has shown that these principles are not always followed by Wikipedia editors (Callahan and Herring, 2011; Harouni, 2009; Massa and Scrinzi, 2013; Yasseri et al., 2014). Studies of NPOV in discourse analysis (Bartlett, 2012; Gredel, 2017; Pentzold, 2009), barring some exceptions (Wessler et al., 2017), have addressed the policy's grey areas as a whole, overlooking the potential of integrative multimodal approaches to account for cross-lingual neutrality breaches. Therefore, in this article I offer another approach, one that tackles NPOV violations along its five dimensions, placing emphasis on how contraventions of one of Wikipedia's primary policies can be explained by means of ideologically motivated lexical and visual choices.

\section{Wikipedia's NPOV and discourse analysis}

Core to the concept of editorial trustworthiness in Wikipedia is the idea that all entries should be written in a neutral, encyclopaedic style. To this end, Wikipedia has a series of overarching policies and guidelines aimed at safeguarding the reliability of the information that is provided on the platform. The most relevant of these policies, also known as "pillars" or essentials, is NPOV. This policy states that content in Wikipedia should be presented "fairly, proportionately, and, as far as possible, without editorial bias", including "all [of] the significant views that have been published by reliable sources on a topic" (Wikipedia, 2019a). NPOV also explains that neutrality does not imply objectivity, and that it can be achieved by employing "neutral language". The same policy gives a series of pointers on how to stay away from biased language:

1. Avoid stating opinions as facts.

2. Avoid stating seriously contested assertions as facts.

3. Avoid stating facts as opinions.

4. Prefer nonjudgmental language.

5. Indicate the relative prominence of opposing views.

Besides language considerations, NPOV relies on the principle of balance or due and undue weight. This principle states that "articles should not give minority views or aspects as much of or as detailed a description as more widely held views or widely supported aspects" (Wikipedia, 2019a). In other words, a Wikipedia entry should avoid opinions held by a minority. Nonetheless, there are some notable exceptions, and NPOV allows for some flexibility when it comes to alternative viewpoints if these are deemed to be relevant by the Wikipedia community. The same policy illustrates this point by providing the example of the English Wikipedia entry for the Earth, which does not mention modern support for the flat Earth concept (Wikipedia, 2019a).

As mentioned earlier, NPOV is not always perfectly implemented, with a group of articles being written in a non-neutral style that contravenes some, if not all, of the aforementioned recommendations (Yasseri et al., 2014). Moreover, the same entries usually exhibit a lack of balance, sometimes with deliberate omissions or highlights. This fact is supported by previous research on the ambiguity of NPOV (Callahan, 2014; Matei and Dobrescu, 2011), as well as on metalanguage and neutrality in Wikipedia (Bartlett, 2012). Matei and Dobrescu's (2011) conclusion that neutrality cannot be achieved in a pluralistic environment such as Wikipedia is reinforced by Bartlett's (2012, p. 699) findings that "neutral" language ultimately depends on "the very specific position of Wikipedia editors".

On a more general level, studies of digital discourse analysis are relatively recent, and researchers in the field face the challenge of developing new tools to cope with rapid advances in technology. To this end, some scholars have endeavoured to readapt frameworks used in traditional discourse analysis or, as Jones et al. (2015, p. 2) call it, "analogue analysis". However, the complexity and diversity of the fast-growing digital world make this task demanding. As a result, there are many analytical frameworks in place aimed at tackling the idiosyncratic multimodality of the online space (Jones et al., 2015). Gredel (2017, p. 102), for instance, calls for a convergence of methods and combines Foucauldian discourse analysis with digital conversation analysis in her study of neutrality disputes in Wikipedia.

Pentzold and Seidenglanz (2006) are widely credited as being the first scholars to have applied Foucault's discourse theory to Wikipedia. In their seminal study, Pentzold and Seidenglanz (2006, p. 62) explore the platform's ability to facilitate effective negotiations and disputes. They do so by gathering data from different communication channels within Wikipedia, showing that interaction among volunteers translates into significant changes to encyclopaedic entries. According to Pentzold and Seidenglanz (2006, p. 66), Wikipedia editors engage in a series of power/knowledge relations, explained by a concomitant exchange of messages. In these exchanges, overarching policies such as NPOV are often invoked by the parties in an attempt to support their arguments and justify editorial changes.

Myers (2010, p. 147) observes that neutrality in Wikipedia is unattainable because (all) processes of knowledge production 
involve making assumptions from a particular stance. Therefore, NPOV should not be considered a goal but rather a "rhetorical device for relocating "neutrality" close to one's own position" (Myers, 2010, p. 147). Myers's approach to NPOV-as well as Bartlett's (2012) - is certainly relevant to the present study to the extent that it brings to the surface the influence of ideological stance on the interpretation of neutrality in Wikipedia. Perhaps even more revealing is Ensslin's (2011, p. 543) assertion that Wikipedia's intended multilingualism fails to "address the complex cultural, political and ideological idiosyncrasies accompanying individual languages". This problem would explain why NPOV varies from one language version of Wikipedia to another, since each community is given some leeway to establish its own norms and restrictions.

A good example of that is found in a recent study by Vaisman et al. (2018), which tackles the impact of nonhuman agents on the enforcement of neutral language use policies in the Hebrew Wikipedia. Their research has drawn attention to the significant role that software robots ("bots") play in that Wikipedia version regarding the implementation of prescriptive language rules. As Vaisman et al. (2018, p. 17) note, these rules are heavily influenced by the ideological positioning of the senior editors of the Hebrew Wikipedia community, who have adopted a conservative stance towards language.

\section{Multimodality and ideological stance}

The term "multimodality" can be traced to the 1920s and was originally associated with the psychology of perception (van Leeuwen, 2012). Notwithstanding, its use in linguistics is relatively recent and owes much to the work of Barthes (1977), who was one of the pioneers in the study of the relation between text and image. In Rhetoric of the Image, Barthes (1977) observes that text-image relations are largely dependent on the cultural and historical context in which they occur. Later linguists further developed Barthes's ideas and acknowledged the semiotic value of pictorial elements. Kress and Leeuwen (1996, p. 17), for instance, hold that texts as cultural constructs consist of visual and verbal elements that are interwoven but remain independent entities. This interconnection has led contemporary discourse analysts to propose integrative approaches under the labels of "multimodal analysis" and "multimodal critical analysis" (O'Halloran, 2004; Machin and Mayr, 2012). O'Halloran (2004, p. 229) notes that "examining [written] language in isolation results in an impoverished view of how that resource is organised for meaning".

Although multimodal discourse analysis pre-dates the digital era, rapid technological advances have caused a surge of interest in studying the multimodal potential of online platforms. Baldry and Thibault (2006) refer to websites as hybrid visual-spatial units resulting from the combination of text and image, where users can "act on the page and obtain responses to their actions" (Baldry and Thibault, 2006, p. 104).

Regarding the relation between multimodality and ideological stance, Martínez Lirola (2006, p. 378) notices that multimodal texts inevitably communicate the ideology of an institution or group of people. In her study of how immigrants are portrayed negatively in Spanish media outlets, Martínez Lirola (2006, p. 380) argues that photos "are crucial in the process of persuading the reader to accept a particular image" of the subject being covered. Similarly, Machin and Mayr (2012) hold that analysing the occurrence of specific lexemes and images is of the utmost importance to gain an insight into the authors' underlying beliefs and motivating reasons.

Wessler et al. (2017, p. 201), who studied ideologically motivated neutrality violations across four language versions of Wikipedia, define Wikipedia entries as "multimodal documents" characterised by the convergence of images and text. As such, Wikipedia entries provide researchers with the opportunity to tackle cross-lingual violations of NPOV through the analysis of both images and textual material. In their paper, Wessler et al. (2017) examine how Alexis Tsipras, then Prime Minister of Greece, is described across four language versions of Wikipedia. To this end, they perform a micro multimodal analysis of a set of images depicting the politician in Wikipedia entries, paying attention not only to visual content but also to the captions accompanying the photos. Their investigation found that the images and the captions used to portray Tsipras varied considerably across different versions of the user-driven encyclopaedia, thus suggesting that images are likely to be as biased as texts, and that captions are often used to "enhance that bias" (Wessler et al., 2017, p. 202).

\section{Methods}

Building on previous research on NPOV violations in Wikipedia, in this paper I conduct a multimodal critical discourse analysis (O'Halloran, 2004) of selected data from the English and Spanish Wikipedia entries for the Falklands/Malvinas War. The methodological framework selected for this study integrates some of the analytical tools used by O'Halloran (2004) and Machin and Mayr (2012). Thus, the analysis of images centres primarily on salience, the elements that are usually foregrounded to draw the readers' attention (O'Halloran, 2004, p. 230; Machin and Mayr, 2012, p. 54). Salience can be achieved by emphasising certain meanings. For example, through the use of captions, but also by using suggestive or potent cultural symbols intended to convey a particular message to the readership (Machin and Mayr, 2012, p. 56).

The analysis of verbal content is led by the processes of scanning (Kress and Leeuwen, 1998; O'Halloran, 2004), overlexicalisation (Machin and Mayr, 2012), and lexical suppression or absence (Machin and Mayr, 2012). The first of these terms, scanning, was coined by Kress and Leeuwen (1998). Driven by the Centre of Visual Impact or CVI, scanning is the ability that readers have to make connections between different elements in a text (O'Halloran, 2004, p. 231). Such elements stand out from the rest; their salience is largely determined by contrast, i.e., the particular position in which they occur in the text. For instance, most speakers of European languages learn to read from left to right and from top to bottom. Consequently, introductory elements such as a book cover, the abstract of a journal article, or the headlines of a newspaper should not be overlooked as potential CVI. These parts of the text provide fertile ground for processes of overlexicalisation and lexical suppression. Both are used by Machin and Mayr (2012, p. 37) to describe the proliferation of certain lexemes and their intended absence, respectively. Overlexicalisation and lexical suppression are normally good indicators of ideological contention (Machin and Mayr, 2012, p. 37).

With the methodological framework in place, the data gathered for the analysis of cross-lingual violations of NPOV came from the 1st to 6th March 2019 versions $^{1}$ of English and Spanish Wikipedia entries for the Falklands/Malvinas War-an international conflict that broke out in April 1982, between Argentina and the United Kingdom, over the sovereignty of the South Atlantic archipelago. After two months of attacks and skirmishes that ended with the surrender of the Argentine troops, the British forces regained control over the islands on 14th June 1982.

The rationale for the selection of the data is motivated by the likelihood that the two entries will exhibit certain ideological bias through the use of specific lexemes and images, and thus violate NPOV. As two independent, non-equivalent entries that describe a relatively recent event between two contemporary nations, "Falklands War" (141,253 bytes) and "Guerra de las Malvinas" 
(152,903 bytes) can be described as covering a controversial subject and as such they pave the way for ideologically motivated editorial choices. Moreover, as the flare-up of hostilities between the two countries began in April 1982, statistical data retrieved from Wikipedia page views show that the two entries usually register annual peaks in the number of visits between March and April, with a consequent increase in editorial activity (Wikipedia, 2019b).

The data analysed in this paper were collected from specific sections of the entries. Images were gathered from the "Aftermath" and "Casualties" sections, whereas textual data were obtained from the table of contents and introductory sections, as well as from a series of posts on the entries' talk pages. Introductions and tables of contents are arguably the most widely read and salient parts of an entry, and they usually provide sufficient data to determine whether there are any violations of NPOV. With regard to talk pages, previous studies have revealed that they are useful tools to understand the dynamics of volunteer coproduction (Ferschke et al., 2012; Jones, 2018; Laniado and Tasso, 2011). As noted by Kopf (2018, p. 11), and as the next sections will show, analysing encyclopaedic content alongside talk pages is a good way to ascertain how seemingly controversial statements are contested by the Wikipedia community of editors.

The analysis is divided into three parts, the first two of which are guided by salience and lexical choices (overlexicalisation and suppression). The third part focuses on how such choices are endorsed or contested by some Wikipedia editors. Analysing the editors' reactions to certain lexical choices made in the entries can shed light on their concealed intentionality, especially since, as Van Dijk (1998) and Machin and Mayr (2012) note, using different sets of words to represent the two sides [of a dispute] is a sign of ideological squaring.

Having set the criteria for analysis, the first part targets content structure and the use of images in the two Wikipedia entries, paying attention to their salient features. The second stage moves on to examine the recurrent use of lexemes (overlexicalisation) and the context in which they occur in the entries. The third section of the analysis focuses on a selected number of postings collected from the entries' talk pages. Given the large number of messages posted on the talk pages, only a set of posts commenting on concrete lexical choices were considered. The usernames of the parties engaged in the debate are public as are the comments posted by them. Nevertheless, their pseudonyms were anonymised when citing them verbatim, since that information was deemed to be irrelevant to the investigation. The next section contextualises the analysis by presenting the metadata: date of creation of the entries, page views within the timeframe analysed, and an overview of the references cited in the entries (number and origin).

\section{Metadata}

The Spanish Wikipedia entry "Guerra de las Malvinas" was created on 20th July 2003 by an anonymous user (Wikipedia, 2019c). According to data retrieved using the page views tool ${ }^{2}$, the page had over 8744 visitors from 1st to 6th March 2019, with a daily average of nearly 1457 views (Wikipedia, 2019d). The entry is preceded by its English Wikipedia counterpart "Falklands War", first edited on 19th November 2001 from an IP address (Wikipedia, 2019e). ${ }^{3}$ This page was viewed 24,837 times within the same period, with a daily average of almost 4140 visits (Wikipedia, 2019f).

Guerra de las Malvinas. In the 6th March 2019 version of "Guerra de las Malvinas" there was a comprehensive list of 184 references retrieved from 137 unique sources (Wikipedia, 2019g).
The entry contained a fairly balanced number of Argentine and British sources (45 and 48, respectively). The latter were also found in the English Wikipedia entry, which could be indicative of cross-referencing. This practice is not uncommon in Wikipedia, where editors from different communities often read a given entry in another language and translate specific phrases, sections or paragraphs into the target language. In doing so, they incorporate the original source into the translation. Regarding the Argentine sources cited in "Guerra de las Malvinas", the list of references showed a wide range of authors from that country, as well as institutional websites and mainstream newspapers, most notably La Nación and Clarín.

Falklands war. "Falklands War" had 160 references linked to the text, coming from 102 different sources (Wikipedia, 2019h). ${ }^{4}$ Of these, 58 were British and 19 were of Argentine origin. Within the British sources, the data showed a clear preference for quoting information from mainstream media outlets such as the BBC and The Guardian. The multiple English Wikipedia editors involved in the entry also used 21 printed British sources, most of which refer either to well-known history scholars or to veterans of the war. Freedman's book entitled The official history of the Falklands Campaign (2004) is by far the most cited non-digital source throughout the entry. The Argentine references, on the other hand, were taken mostly from government or institutional websites, followed by online newspapers. An overwhelming majority of the sources consulted by editors are written in English, with only 20 of the 102 sources being from Spanish-speaking outlets or authors.

\section{Salience: images and table of contents}

I shall begin the analysis by drawing attention to one remarkable difference between "Falklands War" and "Guerra de las Malvinas" regarding the use of images to illustrate the body of the text. While the English Wikipedia entry displays memorial pictures from both sides of the conflict (see Fig. 1), the 1st to 6th March 2019 versions of the Spanish Wikipedia entry (Fig. 2) only feature images of fallen Argentine soldiers and memorials. The first of these pictures shows rows of graves in Darwin Cemetery, Falkland Islands, where hundreds of members of the Argentine military personnel that died during the conflict were buried. The second picture was taken in Plaza de San Martin, Buenos Aires, where a memorial paying tribute to the Argentine casualties was erected in 1989 following a decree signed by President Carlos Menem (b. 1930). The third and last of these photos (Fig. 3) can be found in the section entitled "Consecuencias de la guerra" [The aftermath of the war]. The image shows a white wall located in Los Antiguos, Santa Cruz province, Patagonia, containing graffiti with the message "las islas fueron, son y serán (de) Argentina" [the islands were, are and will be (part of) Argentina], alongside a map of the archipelago surrounded by the Argentine national flag. This claim is reinforced by a caption that is attached to the photo, in which readers are informed that "según la Constitución Argentina, la [sic] Malvinas es un asunto irrenunciable del pueblo argentino" (Wikipedia, 2019g) [according to the Argentine Constitution, the Malvinas/Falklands is an inalienable right of the Argentine people].

It can be argued that the use of specific photos, as well as the omission of others, is intended to make readers sympathise with one of the sides: the victims. By uploading only photos of Argentine casualties and memorials, the Spanish Wikipedia editors involved in the entry are circumventing NPOV. The third image, in particular, brings to the foreground the Argentine claim over the Falklands by adding a caption that is arbitrary. Unlike the captions objectively depicting the cemetery and the memorial 


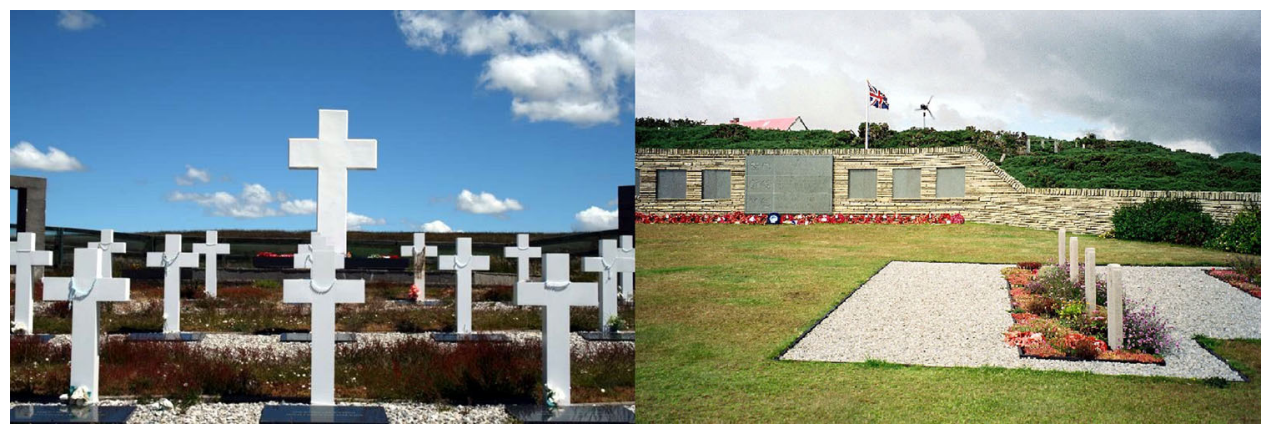

Fig. 1 "Argentine cemetery", the Argentine Military Cemetery, on East Falkland (photo by Chris Pearson, Flickr). "San Carlos Cemetery", the British Military Cemetery at San Carlos, also on East Falkland. The two pictures are used to illustrate textual content from the "Casualties" section of the English Wikipedia entry "Falklands War". The first photo in the figure is covered by the Creative Commons Attribution 2.0 Generic License. The second photo is in public domain.

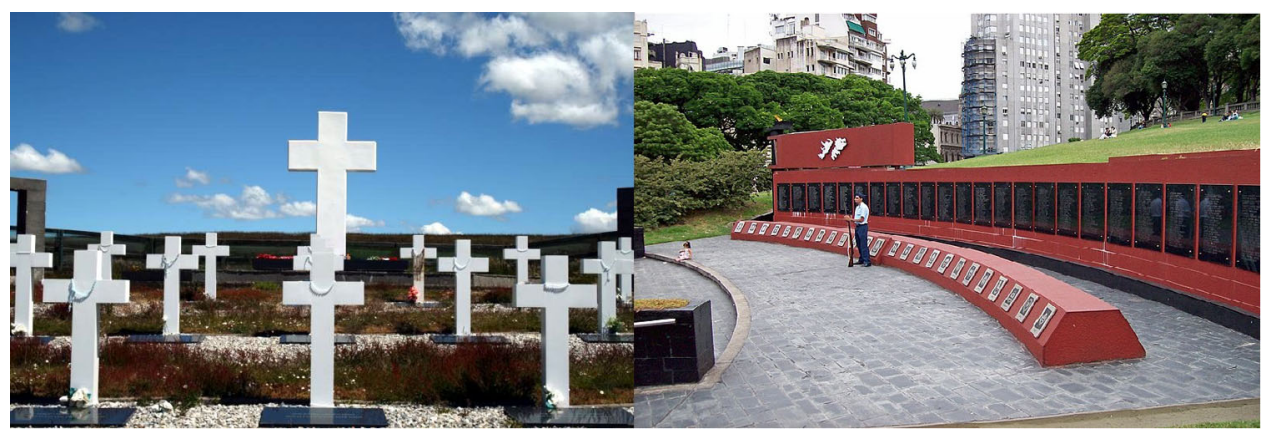

Fig. 2 "Argentine cemetery". The Spanish Wikipedia entry "Guerra de las Malvinas" features the same photo of the Argentine Military Cemetery, on East Falkland, with the caption "Cementerio de Darwin" (Darwin Cemetery). "Monumento Malvinas Plaza San Martin I", taken in Plaza San Martín, Buenos Aires, shows a memorial to the Argentine soldiers that died during the war. The second photo is in public domain.

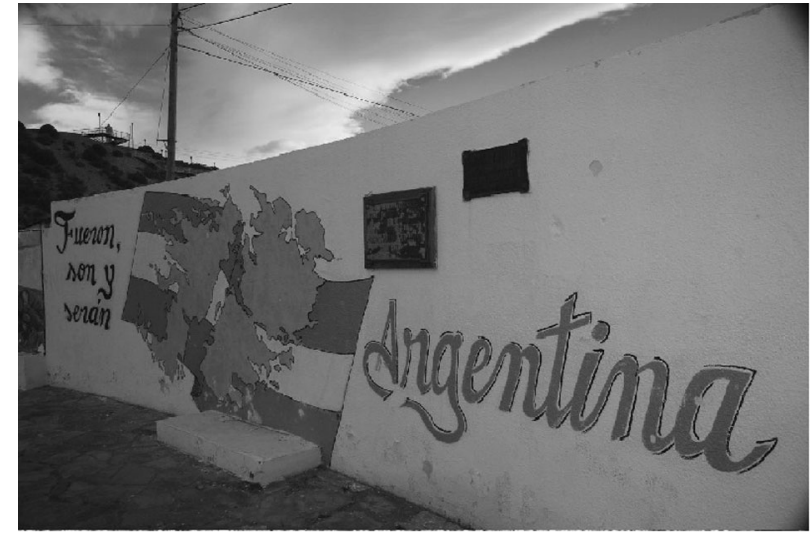

Fig. 3 "Las Islas Malvinas". This monochromatic photo contains graffiti expressing Argentina's claim over the islands. It is used to illustrate the "Aftermath of the war" section of "Guerra de las Malvinas". Retrieved from Wikimedia Commons and originally uploaded to Flickr by Vera \& JeanChristophe. The photo is covered by the Attribution-ShareAlike 2.0 Generic License (CC BY-SA 2.0).

in photos one and two, the third caption does not describe the photo itself but rather makes a claim: that Argentina will never give up the Falklands. This declaration is unequivocally strengthened by the image itself, in which the Argentine flag is "wrapping up" the isles. Alongside the use of national symbols and captions (Machin and Mayr, 2012), another perceptible salient feature of the photo is found in its colours. The picture is markedly monochromatic, composed exclusively of shades of grey. A monochromatic colour, grey has connotations of loss and depression.

Other notable salient features are also present in the Table of Contents of both "Guerra de las Malvinas" and "Falklands War". The first section of the Spanish Wikipedia entry is entitled "Las causas" [The causes], whereas the first section of the English Wikipedia article is nothing more than a plain "Prelude". In "Las causas", there is a subtle attempt to justify the reasons that led Argentine dictator Leopoldo Galtieri to make the first move and seize the islands: (a) Argentina's claim is irredentist; (b) the British saw the isles as a problem before the war; (c) the archipelago is geographically strategic because of its proximity to Antarctica (Wikipedia, 2019g). This section also provides an overview of the political climate in both Argentina and the United Kingdom before the outbreak of the war. Interestingly, only a small part of this long section focuses on Britain. In barely two sentences split by a paragraph break, readers find the following information about the United Kingdom prior to 1982 (Wikipedia, 2019g): (a) the country was facing an economic crisis, with miners going on strike against an increasingly unpopular Prime Minister (Margaret Thatcher); (b) the British Navy feared that their troops were going to be reduced within the context of the Cold War.

The English Wikipedia article devotes the second section to explaining the motivations of the "Argentine invasion" of the archipelago, and there is a vast third section dealing with the "British Task Force" and its operations (Wikipedia, 2019h). The Spanish Wikipedia entry (Wikipedia, 2019g), on the other hand, 
offers a broader picture, with a section entitled "La guerra" [The war], followed by a third section called "Apoyo peruano a Argentina" [Peruvian support to Argentina]. Within this section, readers learn that Peru embraced the Argentine cause and offered logistic and diplomatic support to Galtieri's government. Peru's involvement in the war is thus enhanced in the Spanish Wikipedia article, whereas it is briefly mentioned in the English Wikipedia article. In the "Falklands War" entry, Peru's role in the war is less clear, and it is lumped together with the diplomatic endorsement offered to Argentina by other Latin American nations, with the notable exception of Chile. The same can be said of the Commonwealth countries and their public condemnation of the Argentine occupation. Whereas the English Wikipedia article makes that explicit, including a speech by the Prime Minister of New Zealand at the time of the war, that information is nowhere to be found in "Guerra de las Malvinas".

\section{Lexical choices: the invaders as the "other"}

Aside from these revealing omissions, which seem to contravene NPOV's fifth principle (indicate prominence of opposing views), the two entries differ considerably in their lexical choice to refer to the same historical event. In this regard, perhaps one of the most elucidative examples is provided by a moderate process of overlexicalisation in the introductory sections of both Wikipedia entries. The lexeme "invasion" and its Spanish cognate "invasión" are used consistently in these sections to refer to the Argentines and the British, respectively. "Guerra de las Malvinas" begins by describing the arrival of the Argentine fleet in the archipelago as "desembarco" [landing] and the British military action on the South Sandwich Islands as invasion:

(1) La guerra se desarrolló entre el 2 de abril, día del desembarco ${ }^{5}$ argentino en las islas, y el 14 de junio de 1982, fecha acordada del cese de hostilidades en Malvinas, aunque los británicos invadieron las islas Sándwich del Sur y el 20 de junio desalojaron las instalaciones de la Base Corbeta Uruguay de Argentina, en el marco de la Operación Keyhole [The war took place between the 2nd of April, day of the Argentine landing on the isles, and the14th of June 1982, the agreed date for the cessation of hostilities in the Falklands, although the British invaded the South Sandwich Islands, and on the 20th of June they dislodged the Argentinian Uruguay Corbeta Base as part of the Operation Keyhole].

The following sentence reinforces the statement above by using the singular feminine adjective "invasora" [invading] to refer to the status of the islands as being forcefully occupied by an invading world power:

(2) Argentina considera que estos territorios se encuentran ocupados por una potencia invasora [...] [Argentina considers that these territories are occupied by an invading world power...].

In the English Wikipedia entry, the introduction presents the course of events from a radically different angle, describing Argentina as the one that invaded and occupied the archipelago:

(3) The conflict began on 2 April, when Argentina invaded and occupied the Falkland Islands, followed by the invasion of South Georgia the next day in an attempt to establish the sovereignty it had claimed over them (Wikipedia, 2019h).

The "Lead-up to the conflict" section of "Falklands War" develops the narrative further and makes it explicit that the Argentine government invaded the islands:
(4) The Argentine military junta, suspecting that the UK would reinforce its South Atlantic Forces, ordered the invasion of the Falkland Islands to be brought forward to 2 April (Wikipedia, 2019h).

As can be seen, the two entries repeat lexemes that convey the idea of invasion and occupation from the outset to portray the actions undertaken by the two countries. In the Spanish Wikipedia entry, the British are seen as the invaders, whereas in the English-language entry it is the Argentines who are accused of such offence. Admittedly, this explicit use of lexemes in the entries disregards all five NPOV dimensions.

From a discursive point of view, the lexeme "invasion" is loaded with negative connotations, unlike the more neutral "landing". As stated earlier, what is revealing about this choice of words is not the fact they violate NPOV, but, rather, that their usage represents a stance taken by Wikipedia editors from the two language communities. Therefore, its preference over other lexemes such as "landing" can be considered a case of ideological positioning and manipulation. According to Van Dijk (2006, p. 359), discursive manipulation is often achieved by "emphasising Our good things, and emphasising Their bad things". While the overuse of certain lexemes is indicative of ideological positioning, so is their suppression. In this case, the lexemes "invasion" and "occupation" denote the actions undertaken by two different agents. In examples 1 and 2, the Argentines are dissociated from connotations of invasion, whereas examples 3 and 4 retrieved from the English Wikipedia show that the same dissociation also applies to the British. This suggests that none of the editors involved in the entries view their nations as invaders. As noted by Van Dijk (1998) and Machin and Mayr (2012), the purposeful use of sets of words to represent the two sides [of a dispute] is a sign of ideological squaring. These opposing views are discussed in more detail below, where editors of the two Wikipedia versions try to negotiate the use of more "neutral" lexemes.

\section{The "war" taken to the talk pages}

The talk or discussion pages associated with the entries are as large as the entries themselves. This is hardly surprising because hotly contested topics in Wikipedia typically lead to long and sometimes fruitless discussions between peers. For the purposes of this paper, however, only four comments-two from each entry talk page-were selected, because they were thought to be illustrative of the lack of consensus around concepts of war, invasion and occupation. In keeping with the order followed in the previous sections, the first two comments are from the "Guerra de las Malvinas" talk page.

Recuperar las islas [recovering the islands]. As mentioned earlier, a major claim that "Guerra de las Malvinas" makes is that Argentina attempted to gain the islands back, thus suggesting that the archipelago was unlawfully occupied by the United Kingdom. This information was contested on 26th July 2018 (Wikipedia, 2019i) by an anonymous user who argued that "the entry says that Argentina invaded to recover the islands for Argentina. The isles had never belonged to Argentina; hence it is not recovering but obtaining" (own translation). Right after, User 1 (12:35, 26th July 2018) replies to the unidentified user with the following message: "I invite you to read the (entries for the) political and military command of the Falkland Islands and Luis Vernet. If you want a bibliography, you can contact me" (own translation).

The first of the two entries mentioned by User 1 in the discussion is only available in the Spanish Wikipedia, and it refers to the apparent Argentine status of the islands prior to British 
rule. The second entry, "Luis Vernet", is accessible in six language versions of Wikipedia, including English and Spanish. However, whereas the Spanish Wikipedia entry contends that Luis Vernet (1791-1871) was the first Argentine governor of the isles, the English Wikipedia article describes him as a controversial German merchant of Huguenot descent that "established a settlement on East Falkland in 1828, after first seeking approval from both the British and Argentine authorities" (Wikipedia, 2019l). These differences cannot be overlooked as they both sustain and challenge Wikipedia's NPOV. If one only observes the information contained in the Spanish Wikipedia entries cited by User $1, \mathrm{NPOV}$ is not violated, and thus the statement that Argentina recovered the isles would in principle be legitimised. Nevertheless, the English Wikipedia entry for Luis Vernet questions his motivations and their legal value, consequently reinforcing the British claim over the archipelago.

NO fue "guerra" [it was NOT "war"]. On 22nd September 2018 at 22:04, User 2 proposes restricting the use of the lexeme "guerra" [war] to the title instead of using it freely in the text (Wikipedia, 2019i). The reasoning behind their demand seems to be that "guerra" [war] maximises the magnitude of the conflict. They further contend that "I heard the president of the Malvinas Museum in a radio programme; he says that it was not a "war" but rather a "military conflict". We already put war in the title, but I suggest that we do not overuse that word in the article that, besides, is highly redundant" (own translation). Their source is immediately contested by User 3 on 23rd September 2018 at 16:57, who argues that "beyond the personal opinion of the director of a museum, Argentina officially refers to the conflict as "Guerra de las Malvinas", as it is established by Law 25,370 that declares the 2nd of April as "Day of the Veteran and the Fallen in the war in Malvinas". To bolster their argument, User 3 provides an external link to the website of the Argentine embassy in Italy (Wikipedia, 2019i).

British victory, but continued Argentinian claim. In the English Wikipedia entry talk page, User 4 opens a thread (13:14, 21st April 2016, Archive 13) asking editors to elaborate on why the British accepted the Argentine claim over the islands after the war was over. Two months later, User 5 (03:43, 24th June 2016, Archive 13) replies that "The British could not do anything about the claim; they recognised nothing" (Wikipedia, 2019j), to which User 6 (11:40, 24th June 2016, Archive 13) adds that "Technically, User 4, the UK liberated the islands from conquest, not reconquered" (Wikipedia, 2019j). As seems clear, two central elements of this discussion are (a) the reasons why the United Kingdom accepted the Argentine claim over the islands, and (b) whether Britain liberated the islands from Argentina or simply reconquered them. The second aspect is relevant from a discursive point of view because the difference between conquer and reconquer goes beyond mere nuances of meaning. As noted in the analysis of lexical choices, in "Guerra de las Malvinas" the lexeme "recuperar" [recover] implies that the Falklands were previously owned by Argentina. Unsurprisingly, that statement is disputed in the English Wikipedia, where the UK-and not Argentina-is the country that is "liberating the islands from conquest". Again, these two sides of the narrative-whether one nation is the liberator or the conqueror - seem at best to go against NPOV, particularly points 4 and 5 .

Invasion?. Something similar occurs with the English lexeme "invasion" and the Spanish cognate "invasión". On 18th February 2010, User 7 (18:11, Archive 10), from the Spanish Wikipedia, expresses their disagreement with how the term is used throughout the English Wikipedia entry, especially to describe the actions undertaken by the Argentine military junta. User 7 argues that "for Argentina [it] was recovery, that's no[t] neutral" (Wikipedia, 2019k). The user's remark triggers a long discussion in which many editors intervene, with the consensus that the lexeme "invasion" should be kept. User 8 (19:27, 18th February 2010, Archive 10) further disputes the validity of User 7's claim by adding that "invasion ${ }^{6}$ is a perfectly neutral term in this case: this was an invasion, and there's no reason why we shouldn't describe it as such". User 7, unsatisfied with User 8's response, asserts that "[we] already reached a consensus in the Spanish Wikipedia. My problem is with the statement "The Falklands War started on Friday, 2 April 1982 with the Argentine invasion and occupation of the Falkland Islands and South Georgia. Not yet read the rest of the article. I purpose [sic] "Landing and occupation"'” (23:59, 18th February 2010, Archive 10). The thread ends with User 8's reaffirmation that "invasion" does not promote the British POV. It's an accurate and neutral term for what happened, and there is no reason at all to remove it" (17:46, 19th February 2010, Archive 10).

This thread encapsulates all the issues that were anticipated at the beginning of this paper. It is revealing of how the ideological stance of Wikipedia editors influences and shapes the information contained in the entries. It also showcases how the Falklands War narrative changes from one language version of Wikipedia to the other. Most importantly, however, it is itself a reflection of how the (over)use of certain lexemes in key parts of the text does not go unnoticed. The fact that they raise voices of dissent is a good indicator of their ideological component.

\section{Conclusion}

The study found that the inclusion of certain images, the structural organisation of the entries, and the overuse or suppression of specific lexemes in particular contexts can be good indicators of ideologically motivated violations of NPOV. The data retrieved from the two entries for the Falklands/Malvinas War show that the use of lexemes with connotations of invasion and occupation is arbitrary. This is further attested by the inclusion of one-sided visual material, as in "Guerra de las Malvinas". Moreover, the examples from the talk pages reveal that the information contained in the two entries is contested by different Wikipedia editors. Discrepancy arises when it comes to concepts such as conquest, liberation, invasion, occupation and recovery. The two Wikipedia entries differ radically in how they apply these terms. In "Guerra de las Malvinas", the British are described as the invading power, whereas Argentina is the liberating force. In "Falklands War", the lexemes "invasion" and "occupation" are consistently used to refer to the actions undertaken by the Argentine forces.

The findings suggest that multimodal discourse analysis can be an effective method to tackle cross-lingual NPOV violations in Wikipedia. If one were to apply the five principles advocated by NPOV narrowly, the two entries would fail the test. However, it seems clear that the interpretation and implementation of NPOV ultimately depend on the consensus reached by each Wikipedia community, showing that neutrality is a local and relative position. Although these results are meaningful, more research is required to assess how images and lexemes are used in other controversial topics in Wikipedia. Future studies could further investigate contested facts across different Wikipedia articles by examining the recurrence of certain lexemes using a corpusgenerated data set.

\section{Data availability}

The data analysed during the study are available at "Guerra de las Malvinas", "Falklands War", and their corresponding Wikipedia talk pages. All links to the data are included in the reference list. 
Received: 27 December 2019; Accepted: 11 March 2020;

Published online: 07 April 2020

\section{Notes}

1 Wikipedia entries, unless protected, can be edited by anyone at any time. This means that entries are subject to change, as editors introduce, delete or modify content. Each change undergone by an entry is registered with a timestamp containing the date and time when the content was altered, as well as the user name of the editor involved. Timestamps are stored in the revision history on the top of each entry. It is therefore possible to track changes by looking at different timestamps within the revision history.

2 The page views tool is one of Wikipedia's internal tools. It allows users to look for quantitative data about a specific entry. Although changes (also known as "edits") to the page do not count as page views, editors may still decide to repeatedly visit the article, affecting the page view tool's count. This is why "visits" is used here instead of "visitors" or "viewers".

3 IP stands for "Internet Protocol". An IP address is a numerical code linked to a device connected to a computer network. When non-registered-often referred to as anonymous-Wikipedia users edit the encyclopaedia, their contributions are saved in the so-called "revision history" along with everyone else's. Each Wikipedia page, whether an entry or a user page, has a revision history that provides information about all the changes undergone by that page.

4 The remaining 25 sources were from the U.S. (11), New Zealand (3), Brazil (1), Denmark (1), Germany (1), Israel (1), the Netherlands (1), Spain (1), Switzerland (1), Turkey (1), Uruguay (1) and Unknown origin (2).

5 The use of italics in the examples indicates emphasis.

6 Idem.

\section{References}

Alexa (2020) The top 500 sites on the web. https://www.alexa.com/topsites. Accessed n.d. 2020

Azer SA (2015) Is Wikipedia a reliable learning resource for medical students? Evaluating respiratory topics. Adv Physiol Educ 39:5-14

Baldry A, Thibault PJ (2006) Multimodal transcription and text analysis. Equinox, London

Barthes R (1977) Rhetoric of the image. In: Barthes R (ed). Image-music-text. Fontana, London, pp. 32-51. (S. Health and trans)

Bartlett T (2012) Lay metalanguage on grammatical variation and neutrality in Wikipedia's entry for Che Guevara. Text Talk 32:681-701

Callahan E (2014) Crosslinguistic neutrality: Wikipedia's neutral point of view from a global perspective. In: Fichman P, Hara N (eds) Global Wikipedia. International and cross-cultural issues in online collaboration. Rowan \& Littlefield, Lanham, pp. 69-84

Callahan ES, Herring SC (2011) Cultural bias in Wikipedia content on famous persons. J Am Soc Inf Sci Technol 62:1899-1915

Ensslin A (2011) What an un-wiki way of doing things: Wikipedia's multilingual policy and metalinguistic practice. J Lang Politics 10:535-561

Ferschke O, Gurevych I, Chebotar Y (2012) Behind the article: recognizing dialog acts in Wikipedia talk pages. In: Proceedings of the 13th conference of the European chapter of the association for computational linguistics. Association for Computational Linguistics, Avignon, France, pp. 777-786

Freedman L (2004) The official history of the Falklands Campaign, Volume 2. War and diplomacy. Routledge, London

Gredel E (2017) Digital discourse analysis and Wikipedia: bridging the gap between foucauldian discourse analysis and digital conversation analysis. J Pragmat 115:99-114

Harouni H (2009) High school research and critical literacy: social studies with and despite Wikipedia. Harv Educ Rev 79:473-494

Hobbs WR, Roberts ME (2018) How sudden censorship can increase access to information. Am Political Sci Rev 112:621-636

Hyman P (2011) Society gender bias at wikipedia? Commun ACM 54:18

Jones $\mathrm{H}$ (2018) Wikipedia as a translation zone: a heterotopic analysis of the online encyclopedia and its collaborative volunteer translator community. Target 31:77-97

Jones RH, Chik A, Hafner CA (2015) Discourse analysis and digital practices. In: Jones RH, Chik A, Hafner CA (eds) Discourse and digital practices: doing discourse analysis in the digital age. Routledge, London, UK, pp. 1-17

Kopf S (2018) Debating the European Union transnationally: Wikipedians' construction of the EU on a Wikipedia talk page (2001-2015). Lancaster University, Lancaster, UK, Ph.D thesis

Kress G, van Leeuwen T (1996) Reading images: the grammar of visual design. Routledge, London
Kress G, van Leeuwen T (1998) The (critical) analysis of newspaper layout. In: Bell A, Garrett P (eds) Approaches to media discourse. Blackwell, Oxford, pp. $186-219$

Laniado D, Tasso R (2011) When the Wikipedians talk: network and tree structure of Wikipedia discussion pages. In: Proceedings of the 5th International AAAI conference on weblogs and social media. The AAAI Press, Stanford, CA, pp. $177-184$

Machin D, Mayr A (2012) How to do critical discourse analysis. SAGE, London, UK

Martin B (2017) Persistent bias on wikipedia: methods and responses. Soc Sci Comput Rev 36:379-388

Martínez Lirola M (2006) A critical analysis of the image of immigrants in multimodal texts. Linguist Hum Sci 2.3:377-397

Massa P, Scrinzi F (2013) Manypedia: comparing language points of view Wikipedia communities. First Monday 18. https://doi.org/10.1145/2462932.2462960

Matei SA, Dobrescu C (2011) Wikipedia's "neutral point of view": settling conflict through ambiguity. Inf Soc 27:40-51

Michelucci P, Dickinson JL (2016) HUMAN COMPUTATION. The power of crowds. Science 351:32-33

Myers G (2010) The discourse of blogs and wikis. Continuum, London, UK

O’Halloran K (2004) Multimodal discourse analysis. Continuum, London, UK

Page R (2014) Counter narratives and controversial crimes: The Wikipedia article for the 'Murder of Meredith Kercher'. Lang Lit 23(1):61-76

Pentzold C (2009) Fixing the floating gap: the online encyclopaedia wikipedia as a global memory place. Mem Stud 2:255-272

Pentzold C, Seidenglanz S (2006) Foucault@Wiki: first steps towards a conceptual framework for the analysis of wiki discourses. In: Proceedings of the WikiSym 2006. ACM Press, New York, NY, pp. 59-68

Vaisman C, Gonen I, Pinter Y (2018) Nonhuman language agents in online collaborative communities: comparing hebrew Wikipedia and Facebook translations. Discourse Context Media 21C:10-17

van Dijk TA (1998) Ideology. Sage, London

van Dijk TA (2006) Discourse and manipulation. Discourse Soc 17:359-383

van Leeuwen T (2012) Critical analysis of multimodal discourse. In: Chapelle CA (ed.) The encyclopedia of applied linguistics. John Wiley and Sons, New York

Warncke-Wang M (2012) In search of the ur-Wikipedia: universality, similarity and translation in the Wikipedia interlanguage link network. In: WikiSym 2012 conference proceedings. 8th Annual International Symposium on Wikis and Open collaboration. WikiSym, New York, NY, pp. 1-9

Wessler H, Theil CK, Stuckenschmidt H, Storrer A, Debus M (2017) "Wikiganda": Detecting bias in multimodal Wikipedia entries. In: Seizov O, Wildfeuer J (eds) New studies in multimodality. Conceptual and methodological elaborations. Bloomsbury Academic, London

Wikipedia (2019a) Wikipedia: Neutral Point of View. https://en.wikipedia.org/ wiki/Wikipedia:Neutral_point_of_view. Accessed n.d. 2019

Wikipedia (2019b) Pageviews analysis: Falklands War. https://tools.wmflabs.org/ pageviews/?project $=$ en. wikipedia.org\&platform $=$ all-access\&agent $=$ user\&start $=$ 2018-03-01\&end=2019-03-06\&pages=Falklands_War. Accessed n.d. 2019

Wikipedia (2019c) Información de «Guerra de las Malvinas». https://es.wikipedia. org/w/index.php?title=Guerra_de_las_Malvinas\&action=info. Accessed n.d. 2019

Wikipedia (2019d) Pageviews analysis: Guerra de las Malvinas. https://tools.wmflabs. org/pageviews/?project=es.wikipedia.org\&platform $=$ all-access\&agent $=$ user\&start $=$ 2019-03-01\&end $=2019-03-06 \&$ pages $=$ Guerra_de las_Malvinas. Accessed n.d. 2019

Wikipedia (2019e) X tools: Falklands War. https://xtools.wmflabs.org/articleinfo/ en.wikipedia.org/Falklands_War. Accessed n.d. 2019

Wikipedia (2019f) Pageviews analysis: Falklands War. https://tools.wmflabs.org/ pageviews/?project $=$ en.wikipedia.org\&platform $=$ all-access\&agent $=$ user\&start $=$ 2019-03-01\&end=2019-03-06\&pages=Falklands_War. Accessed n.d. 2019

Wikipedia (2019g) Guerra de las Malvinas. https://es.wikipedia.org/w/index.php? title=Guerra_de_las_Malvinas\&oldid=115646317. Accessed n.d. 2019

Wikipedia (2019h) Falklands War. https://en.wikipedia.org/w/index.php? title $=$ Falklands War\&oldid $=894504833$. Accessed n.d. 2019

Wikipedia (2019i) Discusión: Guerra de las Malvinas. https://es.wikipedia.org/wiki/ Discusi\%C3\%B3n:Guerra de las_Malvinas. Accessed n.d. 2019

Wikipedia (2019j) Talk: Falklands War/Archive 13. https://en.wikipedia.org/wiki/ Talk:Falklands War/Archive 13\#British_victory, _but_continued_Argentinian_claim. Accessed n.d. 2019

Wikipedia (2019k) Talk: Falklands War/Archive 10. https://en.wikipedia.org/wiki/ Talk:Falklands_War/Archive_10\#Invasion? Accessed n.d. 2019

Wikipedia (2019l) Luis Vernet. https://en.wikipedia.org/w/index.php?title=Luis Vernet\&oldid $=862716139$. Accessed n.d. 2019

Yasseri T, Spoerri A, Graham M, Kertész J (2014) The most controversial topics in Wikipedia: a multilingual and geographical analysis. In: Fichman P, Hara N 
(eds) Global Wikipedia: International and cross-cultural issues in online collaboration. Rowman and Littlefield, Lanham, pp. 25-48

Zhang A, Livneh D, Budak C, Robert L, Romero D (2017) Crowd development: the interplay between crowd evaluation and collaborative dynamics in Wikipedia. In: Proceedings of the ACM on human-computer interaction. ACM, New York, NY, p. 119

\section{Acknowledgements}

I would like to express my gratitude to Dr Maeve Olohan for her guidance and enthusiastic encouragement. I would also like to extend my thanks to Néstor Singer Contreras and Chris Rhodes for their constructive critique of this project.

\section{Competing interests}

The author declares no competing interests.

\section{Additional information}

Correspondence and requests for materials should be addressed to J.G.G.-G.

Reprints and permission information is available at http://www.nature.com/reprints
Publisher's note Springer Nature remains neutral with regard to jurisdictional claims in published maps and institutional affiliations.

(c) Open Access This article is licensed under a Creative Commons Attribution 4.0 International License, which permits use, sharing, adaptation, distribution and reproduction in any medium or format, as long as you give appropriate credit to the original author(s) and the source, provide a link to the Creative Commons license, and indicate if changes were made. The images or other third party material in this article are included in the article's Creative Commons license, unless indicated otherwise in a credit line to the material. If material is not included in the article's Creative Commons license and your intended use is not permitted by statutory regulation or exceeds the permitted use, you will need to obtain permission directly from the copyright holder. To view a copy of this license, visit http://creativecommons.org/ licenses/by/4.0/.

(C) The Author(s) 2020 